\title{
Evaluation of Fear in Idiopathic Epilepsy Using Population-Based Survey and Bhalla-Gharagozli Fear in Epilepsy Questionnaire (BG-FEQ)
}

This article was published in the following Dove Press journal: Neuropsychiatric Disease and Treatment

\author{
Kurosh Gharagozli ${ }^{1-3}$ \\ Elham Lotfalinezhad ${ }^{4,5}$ \\ Fatemeh $\mathrm{Amini}^{5}$ \\ Vida Saii ${ }^{\text {I }}$ \\ Devender Bhalla (iD) ${ }^{6-8}$ \\ 'Iran Epilepsy Association, Tehran, Iran; \\ ${ }^{2}$ Department of Neurology, Shahid \\ Beheshti University of Medical Sciences, \\ Tehran, Iran; ${ }^{3}$ Brain Mapping Research \\ Centre, Shahid Beheshti University of \\ Medical Sciences, Tehran, Iran; \\ ${ }^{4}$ Department of Health Education and \\ Promotion, Tabriz University of Medical \\ Sciences, Tabriz, Iran; ${ }^{5}$ Iranian Research \\ Centre on Aging, University of Social \\ Welfare and Rehabilitation Sciences, \\ Tehran, Iran; ${ }^{6} \mathrm{Nepal}$ Interest Group of \\ Epilepsy and Neurology (NiGEN), \\ Kathmandu, Nepal; ${ }^{7}$ Sudan League of \\ Epilepsy and Neurology (SLeN), \\ Khartoum, Sudan; ${ }^{8}$ Pôle Universitaire \\ Euclide Intergovernmental UN Treaty \\ 49006/49007, Bangui, Central African \\ Republic
}

Correspondence: Devender Bhalla Email bhalla@mail.euclid.int

\begin{abstract}
Introduction: The primary objective of this study was to evaluate fear related to epilepsy and its treatment among those with idiopathic epilepsy. Our secondary objective was to estimate the psychometric properties of a brief Bhalla-Gharagozli Fear in epilepsy Questionnaire (BG-FEQ).
\end{abstract}

Methods: We conducted patient-finding exercise in our study areas through various means to obtain subjects with idiopathic epilepsy. We carefully examined each patient through a detailed case-history examination. Following that, we evaluated fear related to epilepsy by using Bhalla-Gharagozli Fear in Epilepsy Questionnaire (BG-FEQ) across two broad domains: epilepsy and pharmacotherapy.

Results: The study obtained 52 subjects (39.0 years; $45.0 \%$ males, $70.0 \%$ married, $35.0 \%$ unqualified, $85.0 \%$ active epilepsy, $80.0 \%$ generalized seizures) with idiopathic epilepsy. The alpha coefficient was 92.8 , with no item-specific coefficient of $\leq 0.91$. The alpha coefficient was 0.90 and 0.93 for reporting a "yes" and "no" to the items, respectively. We obtained a two-factor structure of BG-FEQ that provided a cumulative variance of $83.6 \%$. The majority $(65.0 \%)$ reported at least one fear. The per-patient mean number of the fear element was $2.1(95 \% \mathrm{CI}$ 1.1-3.3), which differed significantly for males and females (1.1, 95\% CI $0.4-2.6$ and 3.0, 95\% CI 1.4-4.6, respectively, $\mathrm{p}=0.03$ ). The most frequent fear was that of addiction and the bad effects of anti-seizure medications (both $45.0 \%$ ). Upon bootstrap regression after constraining gender, the fear elements were associated with illiteracy, difficulty in understanding epilepsy and sleeping in a prone position. The sample power was $99.0 \%$.

Conclusion: There was a significant representation of fear among those with idiopathic epilepsy, especially among the females, particularly the fear of brain tumour, premature death and more frequent/severe seizures over time. At least $65.0 \%$ of idiopathic subjects are likely to be affected by at least one fear. The essential mitigating approach should be the education of practitioners towards better identification and therapeutic handling of comorbid constructs, and also for the education of patients and their caregivers towards better awareness and prevention. There is also a need for formal Epilepsy Educators towards better awareness, therapeutic support and prevention of epilepsy.

Keywords: idiopathic epilepsy, epidemiology, behavioural, fear, mental health

\section{Introduction}

Those with epilepsy are "more than their mere illness". By this, we mean that satisfactory therapeutic outcome and social and physical wellbeing of those with epilepsy also depend upon timely identification and mitigation of comorbid cognitive, behavioural, emotional or psychosocial issues that inadvertently arise due to epilepsy. ${ }^{1}$ 
One such issue is the element of fear related to epilepsy or its treatment. Fear is an important parameter to assess in general, and it has both positive and negative connotations. For instance, the perceived fear of untoward consequences from the illness may lead patients to espouse health-promoting actions. But, on the other hand, the perceived fear of adverse effect from medications may keep patients away from up taking them adequately, etc. ${ }^{2}$ Overall, fear has an association with medication compliance, parasuicidal behaviour, aggression, lower quality of life, tenuous relationships with peers, poor education and low income. ${ }^{3,4}$

In epilepsy, fear is one of the forgotten comorbid psychopathological constructs that is rarely recognized. However, it is seen that epilepsy patients commonly fear death and brain damage resulting from their seizures. ${ }^{3}$ Among those with epilepsy, the elements of fear may arise due to many reasons. For instance, the unpredictable and sudden onset nature of seizures may lead to anxious anticipation or distress of the consequences from a feared situation (ie, epilepsy), which may, in turn, interfere with one's physical, mental and social functioning. Since epilepsy is a chronic ailment and requires uptake of treatment over a long period, the fear may also arise due to the pervasive effects of epilepsy as a long-term illness. Some epilepsy patients are seen to develop an actual phobic anxiety state relating to their seizures. ${ }^{4}$ Fear is also important in the diagnosis of epilepsy because the patients could be considered as having panic attacks, which may delay the diagnosis of epilepsy. ${ }^{5}$ Apart from the brief mention, fear in epilepsy does not appear much in the literature. ${ }^{4}$

Thus, with such a vision, the primary objective of our study was to estimate fear related to epilepsy and identify its sociodemographic and clinical correlates among those with idiopathic epilepsy. Our secondary objective was to measure the psychometric parameters of a brief fear in epilepsy questionnaire. We consider that our work would provide a reason to seek better identification of comorbid psychopathologies, which, in turn, may support mental health, therapeutic optimization and outcomes among affected epilepsy subjects.

\section{Methods}

We identified all adult subjects (15+ years of age) of both gender with idiopathic epilepsy, ${ }^{6}$ who were interested in participating, were resident (for at least six months), otherwise able and belonged to any of the 26 health house areas of Demavend. Throughout the villages of the entire country, health houses maintain a structured household file for every household that comes under their jurisdiction to record every health-related event through regular and continuous contact with their concerned population. This kind of patient identification remains continuous.

The health houses are run by trained local employees, who are attached to concerned district hospitals. As additional patient-finding measures, we implemented supplementary verbal information campaigns through health houses for those who may be interested in taking costfree convenient consultation at home by city specialists. We also made additional inquiries from the village residents and fellow patients upon domestic health visits. ${ }^{7-9}$

All patients were re-examined and re-diagnosed with the help of a structured and detailed case-history examination. This examination included capturing details on sociodemographic aspects, past medical history, the natural history of epilepsy and seizures, risk factor exposure, precipitating factors, clinical examination, electroencephalogram (EEG) and CT/MRI results, and treatment aspects (both traditional and modern). The criterion for the diagnosis of epilepsy was a clear description of the recurrent and paroxysmal time-limited change in motor activity or behaviour. The inclusion did not have acute symptomatic seizures (ie, a clinical seizure with a close temporal association with a documented brain or systemic insult), febrile seizures (ie, seizures occurring in association with febrile illness), or a single isolated seizure. As per convention, EEG was not the basis for diagnosing epilepsy. The consciousness was the main discriminator. We categorized seizures based on "best fit" seizure classification from the information that we collected from each subject. ${ }^{10}$

Also, we categorized our patients based on the etiological type as idiopathic. These are the ones for whom no conventional underlying etiological factor was confirmed or suspected to be present, either currently or in the past. Those with symptomatic and cryptogenic epilepsies were discarded and not processed further.

We evaluated fear related to epilepsy by using BhallaGharagozli Fear in epilepsy Questionnaire (BG-FEQ). We structured our questionnaire under two broad components related to plausible representation and perception of the consequences of epilepsy and anti-seizure medications (ASMs). These included the fear of (a) brain tumour, (b) premature death, (c) more frequent/severe seizures over time, (d) suffocation during seizure attacks, (e) addiction with ASMs, (f) adverse effects with long-term use of ASMs. Upon a review of possible literature ${ }^{2-5}$ and handson experience with epilepsy, we prepared a pool of items 
that possibly represent fear. After that, a series of discussions took place, and we selected those items that were deemed to be most relevant in describing the perceptions of fear in epilepsy while respecting the requirement in terms of relevance, brevity, feasibility, readability, consistency of style and formatting, and clarity of the language. An expert panel comprising of specialists from neurology, mental health, and public health evaluated content validity. We used the responses from this panel to improve the items. The content validity index (CVI) was measured, and a CVI score higher than 0.75 was considered acceptable. ${ }^{11}$ The responses to each of the six epilepsyrelated elements of fear were dichotomous based on the patient's subjective perception about the absence (score zero) or presence (score one) of those elements. Each patient's fear score was the sum of the total number of fear elements that were reportedly present among them, which were then averaged for the entire sample population as well as for the males and females.

All data were systematically analyzed. Wherever required, the data were summarized descriptively in terms of mean, number, frequency, proportion, 95\% confidence interval (CI). We determined the psychometric properties of our questionnaire by measuring the alpha coefficient for all items together and for individual items. Those items that had a low $(<0.3)$ item-test correlation were deleted. Alpha coefficient was also measured groupwise, ie, separately for yes or no to an item. We did exploratory factor analysis (EFA) to determine the possible number of latent factors that items altogether could be categorized into, by using eigenvalue $\geq 1.0$ and factor loadings $\geq 0.40$. We used the scree plot for EFA. For confirmatory factor analysis (CFA), we estimated fit indices, size of residual, and coefficient of determination.

After that, by using logistic regression, we determined the association of individual fear elements with all possible independent variables separately, after constraining the effects of gender. Later, the bootstrap method was used with $100 x$ replication of our sample to determine the odds ratio. In a posthoc manner, we estimated the required sample size and power by using the mean fear obtained as against the ideal situation of no fear. The sample power was estimated after accounting for an alpha of 0.05 , a standard deviation of 3.0, sample size, and the mean number of fear elements obtained. Lastly, we received informed consent from all subjects before permitting their participation. We obtained ethics approval from the Institutional Review Board of Shahid Beheshti University of Medical Sciences. This study was conducted in accordance with the Declaration of Helsinki.

\section{Results}

We recruited a total of 52 subjects with idiopathic epilepsy. The clinical and sociodemographic description is as follows: median age (39.0, 95\% CI 33.3-44.7), 45.0\% males, $70.0 \%$ married and $35.0 \%$ illiterate. The average frequency and duration (onset to recovery) of seizures in the last 30 days were 1.5 seizures (95\% CI $0.7-2.3$ ) and 0.9 (95\% CI 0.2-1.7) minutes, respectively. Active epilepsy was present in $85.0 \%$ of subjects, $80.0 \%$ had generalized seizures $(68.7 \%$ tonic-clonic, $25.0 \%$ myoclonic, $6.2 \%$ absence), $65.0 \%$ had an EEG, of which only $25.0 \%$ had abnormal EEG findings including generalized spikewave complex and polyspikes, and focal slowing with or without spikes. Eighty percent of subjects had a CT/MRI scan, of which none had a structural lesion or any other abnormality.

\section{Psychometric Properties}

The alpha coefficient was estimated to be 92.8 , while none of the items had this coefficient lesser than 0.91. For individual items, the item-test correlation was no less than 0.79. By group, the alpha coefficient was 0.90 and 0.93 for those reporting a yes and those reporting a no to the questionnaire items, respectively. Upon EFA, we found a two-factor structure for our questionnaire with a cumulative variance of $83.6 \%$, Figure 1 . The KMO for sampling adequacy was 0.80 . Upon CFA, we found a $97.0 \%$ coefficient of determination, 0.80 fit indices, and a small (0.05) standardized residual. In a posthoc measure, we estimated the required sample size and power for the mean fear of 2.1 as against the ideal situation of no fear, and the required sample was 22 . The power of our sample was $99.0 \%$ at an alpha of 0.05 , a standard deviation of 3.0, a sample size of 52, and a mean number of fear elements of 2.1 .

\section{Fear Assessment}

The majority $(65.0 \%)$ of subjects reported having at least one fear element. The mean per-patient number of fear elements for the overall population was 2.1 (95\% CI 1.1-3.3, range 0-6), which, by gender, was $1.1,95 \% \mathrm{CI}$ 0.39-2.6 and 3.0, 95\% CI 1.4-4.6, respectively, $\mathrm{p}=0.03$ for the males and females, respectively. Among the entire sample population, the most common fear present was the fear of addiction and adverse effects of ASMs over 


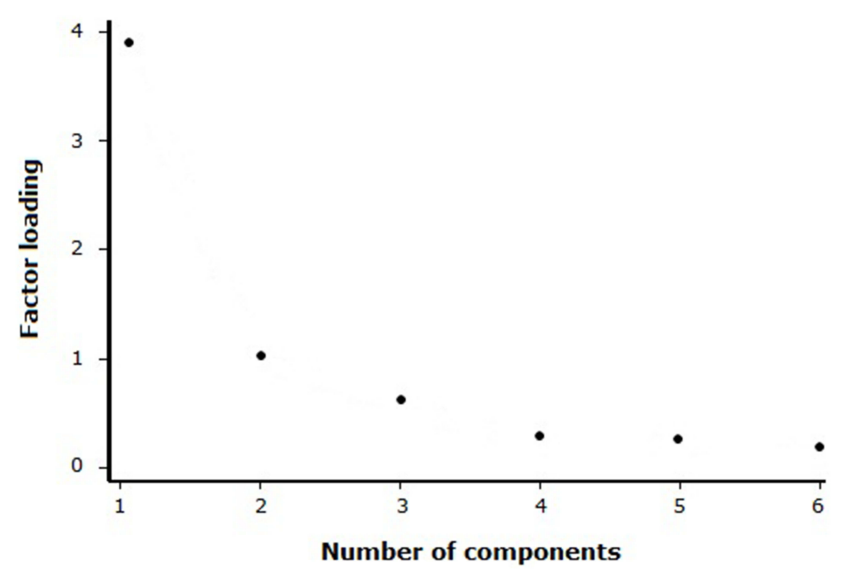

Figure I A scree plot that shows a two-factor latent structure of the BhallaGharagozli Fear in Epilepsy Questionnaire (BG-FEQ) regarding fear related to epilepsy and anti-seizure medications.

the long term, which was reported by $45.0 \%$ subjects, each. Other fear elements were the fear of having more frequent/severe seizures over time $(35.0 \%)$, fear of brain tumour $(35.0 \%)$, fear of premature death $(30.0 \%)$, and the fear of suffocation during seizure attack $(25.0 \%)$.

We found that the mean grade of individual fear elements differed between males and females over a scale of zero to one. These elements were the: fear of: brain tumour $(0.1,95 \%$ CI $0.01-0.4$ and $0.5,95 \%$ CI $0.2-0.9, \mathrm{p}=0.02)$, premature death $(0.1,95 \%$ CI $0.01-0.4$ and $0.4,95 \%$ CI $0.1-0.8, p=0.05)$, and more frequent $/$ severe seizures over time $(0.1,95 \%$ CI $0.01-0.4$ and $0.5,95 \%$ CI $0.2-0.9$, $\mathrm{p}=0.02$ ). There was no such gender difference regarding the fear of suffocation, fear of addiction or the fear of adverse effects with the use of ASMs, Table 1. Upon logistic regression after constraining the impact of gender and bootstrapping of our sample the 100 times, the fear elements were associated with several factors, Table 2.

\section{Discussion}

It was necessary to conduct this study for many reasons. For instance, the lay beliefs about epilepsy may help to understand the patient's cognitive or emotional response to their illness, ${ }^{12}$ which may pave a way to influence their coping strategies and in turn their therapeutic outcomes. ${ }^{13}$ As an example, many subjects with epilepsy never achieve clinical remission despite numerous therapeutic options, ${ }^{14}$ due to which, their routine life continues to remain affected. So, focusing on the patient's comorbid psychopathological constructs may provide treating physicians the ways to deliver results beyond mere symptomatic control, which may, in turn, normalize patient's lives. ${ }^{15}$
Moreover, there are reasonable reasons for enquiring about the elements of fear among those with epilepsy because, unlike many other chronic diseases, the onset of symptoms (ie, seizures) in epilepsy is sudden and unexpected. This sudden onset is against, for instance, the theory of locus of control, which is closely linked to the risk of poor psychopathological states. ${ }^{16}$ Likewise, we included only those with idiopathic epilepsy as they are unique in the sense that, by definition, the underlying cause of their epilepsy is not known, ${ }^{6}$ which goes against the theory of causal inference. For example, the fear elements were related to the difficulty in understanding the nature of epilepsy and why do seizures start and stop (Table 2).

The methods of our study were adequately robust. For instance, we derived our sample from the general population, and the participants were resident and of both genders. Thus, we did not have selective patients that are otherwise possible with other study designs. We used the bootstrap method with 100 times replication, which means that we derived our results after replicating the application of our sample 100 times. We provided our results in terms of effect size, which does not depend upon the sample size, unlike other measures of association. Our sample had high statistical power. ${ }^{17}$ Furthermore, our questionnaire relates well to many common representations of fear that patients may have about their epilepsy or its treatment. For instance, the fear of death or brain damage ${ }^{3}$ or poor general perception about the safety of ASMs. ${ }^{2}$ Our questionnaire also relates well to many theoretical frameworks, such as the appraisal theory of emotion or cognitivemediational theory. These theories assert that our emotions (ie, fear) are determined by our appraisal of the fear stimulus (ie, epilepsy or its treatment).

We performed a psychometric assessment of our questionnaire; a tool that was not available earlier for assessing the elements of fear in epilepsy and for those from a nonwesternized context. A lack of valid intervening tools is one of the reasons for many critical comorbidities to remain undetected on time, ${ }^{18}$ even though effective solutions are available for mitigating them in epilepsy. ${ }^{15}$ The alpha coefficient of internal consistency was considerably higher than the usual criteria of 0.70 . The high alpha coefficient means that all our elements were in line with each other to measure a common underlying construct. Also, our questionnaire was not biased to raise one particular type of participant response since the group alpha coefficient for responding a yes to an item $(\alpha 0.90)$, and no to an item $(\alpha 0.93)$ was sufficiently high and similar to each 
Table I The Representation of Fear in Idiopathic Epilepsy

\begin{tabular}{|c|c|c|c|c|}
\hline Parameter & \multicolumn{4}{|l|}{ Result } \\
\hline Mean per-patient number of fear elements present (overall) & \multicolumn{4}{|c|}{$2.1(1.1-3.3)$, range $0-6$} \\
\hline $\begin{array}{l}\text { Mean per-patient number of fear elements (by gender, } \mathrm{p} \text { value from group } \\
\text { comparison) }\end{array}$ & \multicolumn{4}{|c|}{$\begin{array}{l}\text { - Males: I.I (0.4-2.6), range 0-6 } \\
\text { - Females: } 3.0(\text { (I.4-4.6), range 0-6, } \mathrm{p}=0.03 \text {, } \\
\text { - Effect size }(\mathrm{r}) \text { : } 0.4\end{array}$} \\
\hline Frequency of fear elements (overall population) & \multicolumn{4}{|c|}{$\begin{array}{l}\text { - Fear of addiction: } 45.0 \% \text {, } \\
\text { - Bad effects over the long term: } 45.0 \% \\
\text { - Fear of having more frequent/severe seizures over time: } 35.0 \% \text {, } \\
\text { - Fear of brain tumor: } 35.0 \% \text {, } \\
\text { - Fear of premature death: } 30.0 \% \text {, and } \\
\text { - Fear of suffocation during seizure attack: } 25.0 \%\end{array}$} \\
\hline Mean grade by which fear elements are present (overall population) & \multicolumn{4}{|c|}{$\begin{array}{l}\text { - Fear of suffocation during seizure attack: } 0.8(0.5-0.9)^{\mathrm{a}} \text {, range } 0-\mathrm{I} \\
\text { - Fear of premature death: } 0.7(0.5-0.8)^{\mathrm{a}}, \text { range } 0-\mathrm{I} \\
\text { - Fear of brain tumor: } 0.6(0.4-0.8)^{\mathrm{a}} \text {, range } 0-\mathrm{I} \\
\text { - Fear of more frequent/severe seizures over time: } 0.6(0.4-0.8)^{\mathrm{a}} \text {, range } 0-\mathrm{I} \\
\text { - Fear of addiction: } 0.4(0.2-0.7)^{\mathrm{a}} \text {, range } 0-\mathrm{I} \\
\text { - Fear of bad effects over the long term: } 0.4(0.2-0.7)^{\mathrm{a}} \text {, range } 0-\mathrm{I}\end{array}$} \\
\hline \multirow[t]{3}{*}{$\begin{array}{l}\text { Gender-wise comparison of mean grade by which the fear elements are present } \\
\text { (fear type, males, females, score range and } p \text { value, respectively) }\end{array}$} & Brain tumor & $0.1(0.0 \mathrm{I}-0.4)^{\mathrm{a}}$ & $0.5(0.2-0.9)^{\mathrm{a}}$ & $\begin{array}{l}\text { Range } 0-1 \text {, } \\
p=0.02\end{array}$ \\
\hline & Premature death & $0.1(0.0 \mathrm{I}-0.4)^{\mathrm{a}}$ & $0.4(0.1-0.8)^{\mathrm{a}}$ & $\begin{array}{l}\text { Range } 0-1 \text {, } \\
P=0.05\end{array}$ \\
\hline & $\begin{array}{l}\text { More frequent/ } \\
\text { severe seizures over } \\
\text { time }\end{array}$ & $0.1(0.0 \mathrm{I}-0.4)^{\mathrm{a}}$ & $0.5(0.2-0.9)^{\mathrm{a}}$ & $\begin{array}{l}\text { Range } 0-1 \text {, } \\
p=0.02\end{array}$ \\
\hline $\begin{array}{l}\text { No gender difference (ie } p>0.05 \text { ) in the mean grade by which fear elements are } \\
\text { present }\end{array}$ & \multicolumn{4}{|c|}{$\begin{array}{l}\text { - Suffocation during seizure attacks, } \\
\text { - Fear of addiction, and } \\
\text { - Bad effects over long-term use of ASMs }\end{array}$} \\
\hline Group comparison of those with and without fear element & \multicolumn{4}{|c|}{$\begin{array}{l}\text { - Risk of injury/accident: } 14.0(1.2-26.8)^{\mathrm{a}}, \mathrm{p}=0.03 \\
\text { - Difficulty in understanding why seizures start and stop: } 9.6(1.9-17.3)^{\mathrm{a}}, \mathrm{p}=0.03\end{array}$} \\
\hline
\end{tabular}

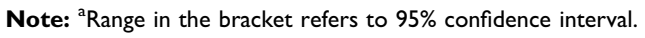

Table 2 The Representation of Fear and Their Association with Sociodemographic Parameters in Idiopathic Epilepsy

\begin{tabular}{|c|c|c|}
\hline $\begin{array}{l}\text { Fear Representation, Fear } \\
\text { of .... }\end{array}$ & Independent Variable & $\begin{array}{l}\text { I00x Bootstrapped Odds Ratio }(95 \% \mathrm{Cl}) \text {, } \\
\text { p-Value }\end{array}$ \\
\hline Premature death & Difficulty in understanding the nature of epilepsy & $26.0,95 \% \mathrm{Cl}^{\mathrm{a}} 3.3-48.7, \mathrm{p}=0.002$ \\
\hline \multirow[t]{4}{*}{ Suffocation during seizure attacks } & Illiteracy & $16.0,95 \% \mathrm{Cl}^{\mathrm{a}} 3.1-28.9, \mathrm{p}=0.00 \mathrm{I}$ \\
\hline & Sleep in prone position & $35.0,95 \% \mathrm{Cl}^{\mathrm{a}} 6.9-63.1, \mathrm{p}=0.00 \mathrm{I}$ \\
\hline & Generalized seizures & $20.0,95 \% \mathrm{Cl}^{\mathrm{a}} 3.6-36.4, \mathrm{p}=0.00 \mathrm{I}$ \\
\hline & Last seizure $\geq 5$ minutes & $9.3,95 \% \mathrm{Cl}^{\mathrm{a}} \mid .3-17.3, \mathrm{p}=0.02$ \\
\hline
\end{tabular}

Abbreviation: ${ }^{\mathrm{a}} \mathrm{Cl}$, confidence interval.

other. Besides these, our factor structure was also adequate, for instance, $97.0 \%$ coefficient of determination, $83.6 \%$ cumulative variance, and 0.05 as the standardized residual. For factor analyses, we used conventional parameters, such as eigenvalue $\geq 1.0$ and factor loading $\geq 0.40$.
Moreover, the anticipated two-factor structure (ie, fear related to epilepsy and fear related to epilepsy treatment) of our questionnaire also got confirmed.

The majority $(65.0 \%)$ of our subjects reported having at least one element of fear. Those who did not report any 
element of fear may have undergone a cognitive process of conditioning. For example, accepting therapeutic value from the uptake of ASMs could be a way people with epilepsy attempt to cure/control their negative emotions [10]. The most frequent fear was related to addiction and untoward effect from the prolonged use of ASMs, Table 1. Fear about ASMs is not unfounded since ASMs are widely perceived as unfavourable among all, be it the physicians, ${ }^{19,20}$ health system actors, ${ }^{21}$ or the patients. ${ }^{2}$ This unfortunate impression of ASMs is there, even though the safety of ASMs has never been adequately and appropriately assessed. ${ }^{22-24}$ So, from these results, we may infer the need for treating physicians to discuss upfront such gaps in the knowledge that we currently have regarding the safety profile of ASMs. If done, such discussions may help patients overcome their apprehension or fear about ASMs, and possibly, to have improved adherence and therapeutic outcomes. ${ }^{15}$ Similarly, from these results, we may also infer yet another reason for the imminent need to adequately assess the safety of ASMs to help have conclusive evidence about the potential risks of using ASMs for epilepsy in different populations. ${ }^{22-24}$

Further, we found that females had a $92.6 \%$ higher perpatient mean number of fear elements than males, $p=0.03$, particularly the fear of brain tumour, premature death and more frequent or severe seizures over time, Table 2 . There can be many possible reasons for this gender difference. For instance, the difference in neurotic personality trait between males and females ${ }^{25}$ and the difference in how the process of fear is perceived by them. ${ }^{26}$ So, we may infer that the assessment of personality trait, especially among female epilepsy subjects, could usefully become a part of regular epilepsy care. The evaluation of personality is meaningful since one's personality type can be modified with therapy, ${ }^{27}$ which may, in turn, help to improve one's attitude and practice regarding day-to-day self-management of epilepsy. ${ }^{28}$ A neurotic trait is one of the most studied traits, and its relation to medication compliance is not unexpected. ${ }^{29}$ Another reason we anticipate for the gender difference in fear could be related to the fact that idiopathic epilepsies are more frequent among females, something we observed as well since $55.0 \%$ of our subjects were female.

We also identified factors that were associated with different elements of fear. For instance, the fear of premature death was related to the difficulty in understanding the nature of epilepsy, and, similarly, illiteracy was associated with the fear of suffocation during seizure attack, Table 2. Literacy is an apparent protective factor because it exposes the patients to different channels of information, which may help to reduce one's negative emotional perception about their illness. ${ }^{30}$ Although literacy is not a factor that can be modified at the patient level, others have shown that health literacy ${ }^{31}$ instead may translate into less harmful psychological elements. ${ }^{30}$ For instance, in our study, the fear of premature death was related to the difficulty in understanding the nature of epilepsy. Moreover, those with and without fear differed in terms of difficulty in understanding why seizures start and stop, Table 2 .

There are plenty of valid ways by which the patient's (or their caregivers) health literacy, and therefore, their apprehension and misrepresentation on epilepsy could be improved, for instance, through domestic health visiting. ${ }^{7-9}$ This multi-purpose approach of domestic health visiting provides home-based convenient services of treatment, follow-up and consistent and repeated message delivery through local intermediaries. The other ways to improve health literacy among the patients are educational interventions that can improve the patient's coping skills and their social and physical wellbeing. ${ }^{15}$ Also, information exchange by treating physicians with their patients (or caregivers) is also critical to improve health literacy, but, something that is rarely done, ${ }^{32}$ even though there are obvious benefits of doing that. ${ }^{33,34}$ For instance, my sister was hospitalized and was to be operated. I was worried and asked her physician many questions. He said why do you ask so many questions? I said I wanted to know about her disease. He said he did not have time to spend an hour to answer my silly questions. ${ }^{35}$ Others have also shown that medical staff is usually unaware of patients' ideas about their condition. ${ }^{36}$ Another way by which health literacy needs and mitigation of negative apprehension of the patients about their illness could be addressed is by setting up entirely novel system of Epilepsy Educators. As an example, there are about 20,000 unemployed nurses in Iran. ${ }^{37}$ Such unemployed health personnel, ex-patients, or general unemployed youths could be trained as Epilepsy Educators for providing their services at home, in the local community, or at dedicated epilepsy care institutions.

Another set of factors that were associated with the elements of fear, particularly the fear of suffocation during seizure attack, were often sleeping in a prone position or when seizures are intense, long-lasting, and generalized. ${ }^{33}$ These are also the patient characteristics that are more likely to die suddenly and unexpectedly, ${ }^{33}$ which shows that different fear elements may not have isolated origins. One example that supports this premise is that for the majority 
of subjects with epilepsy who die unexpectedly, the immediate event before death would be the difficulty in breathing. ${ }^{33}$ So, based on these results, we may infer that patient's apprehensions could be mitigated by providing them with distinctive characteristics (such as those just above) to, in turn, help them distinguish better their risk for untoward consequences from epilepsy. For instance, there is a risk of unexpected premature death among those with epilepsy, but that risk is pretty low. ${ }^{33}$ Similarly, the long-term use of ASMs may render a fear of addiction and adverse effects, Table 1. Still, existing data does not indicate any considerable change in the craving for ASMs. ${ }^{22}$ So, it all comes down to providing the patients (or their caregivers) with right, specific, timely and adequate information based on particular features of their illness.

Our work brings forth new information; for instance, the systematic assessment of fear in epilepsy hardly appears in the literature ${ }^{4}$ even though epilepsy patients commonly fear death and brain damage from their seizures. ${ }^{3}$ Assessing fear in itself is indispensable because the fear may diminish the quality of life, may cause panic, anxiety or phobic disorders, or may even be a deterrent to effective self-management and psychological wellbeing of the patients. ${ }^{4}$ In addition, our study provides a brief, validated instrument for assessing fear, which was not currently available as far as we are aware of. The absence of such intervention tools is one of the reasons that many critical comorbidities may remain undetected, ${ }^{18}$ which is unfortunate since those can otherwise be effectively mitigated through psychotherapies. ${ }^{15}$ Thus, we expect that timely detection and appropriate management of comorbid psychopathological constructs like fear may not only shorten the duration of suffering for those with epilepsy but may also improve their quality of life and social impairment in the long term. ${ }^{38}$ Others have also shown that targeting epilepsy patient's perceptions and misrepresentation may help to reduce their anxiety and help them adjust to their illness. ${ }^{15}$

The application of our study also remains for those of the many epilepsy patients who never achieve clinical remission despite several pharmacotherapeutic options. ${ }^{14}$ Furthermore, our work calls treating physicians to discuss adequately upfront with the patients from early-on the distinctive characteristics of epilepsy. Our work also calls to consider personality assessment and default psychotherapy among female subjects as part of their usual epilepsy care. ${ }^{39}$ Our work also proposes the entirely new concept of Epilepsy Educators which may open professional avenues for unemployed professionals, youths and ex-patients.
We estimated the power of our sample by using sample size and standard deviation as the input, ${ }^{17}$ and we found that our sample power to be adequately high. Lastly, as usual, our work has a few limitations. For instance, there are other possible variables that we did not assess for this work, such as the neurotic trait, etc., that may otherwise help in better understanding of the patient's fear related to their illness. Similarly, our questionnaire had a few elements of fear, and there can be a few other elements, depending upon the cultural context of the patients and opinion of the intervening practitioners. As is the situation with other published studies, our work is also based on self-reports.

Moreover, our study did not have a control group that may have helped to compare the results. All subjects were assessed during a clinical interview for possible psychiatric disturbances, as it is done in a usual clinical set-up. However, we did not use a separate detailed instrument for that to avoid the burden on the participants and possible loss of their participation.

\section{Conclusions}

There was a significant element of fear related to epilepsy and its treatment among our patients, especially among the females, particularly the fear of brain tumour, premature death, and more frequent/severe seizures over time. The gender difference appears to be a sheer biological distinction between males and females on how they perceive and process fear emotion. If our work can do nothing else, at least it can become a reason to call for the additional education of practitioners towards active identification and therapeutic handling of comorbid psychopathological constructs in epilepsy. There is also a need to call for adequate education of patients and their caregivers about the very specific and distinctive characteristics of epilepsy and its treatment, which may help to reduce their undue apprehensions. There is also a need for establishing formal Epilepsy Educators to achieve better awareness, therapeutic support and prevention of epilepsy. Lastly, we think that suitable female subjects with epilepsy would benefit from epilepsy care integrated with a psychotherapy.

\section{Acknowledgments}

We thank Dr Kabiru Abubakar Gulma for taking up the responsibility as a native English speaker for editing the language of the final accepted manuscript. 


\section{Funding}

The funding was procured from Shahid Beheshti University of Medical Sciences and Brain Mapping Research Centre (Shahid Beheshti University of Medical Sciences), Tehran, Iran. The funding agency had no role in manuscript writing, editing, approval, or decision to publish.

\section{Disclosure}

DB receives research funds and attends and gives a talk in meetings that may have been funded directly or indirectly by commercial entities. DB reports grants from Shahid Beheshti University of Medical Sciences. The author is under the authority of treaty-based public International Law. All other authors have no conflicts of interest.

\section{References}

1. Srinivas H, Shah U. Comorbidities of epilepsy. Neurol India. 2017;65 (7):18-24.

2. Chapman S, Horne R, Chater A, Hukins D, Smithson W. Patients' perspectives on antiepileptic medication: relationships between beliefs about medicines and adherence among patients with epilepsy in UK primary care. Epilepsy Behav. 2014;31:312-320. doi:10.1016/ j.yebeh.2013.10.016

3. Mittan R, Locke G. Fear of seizures: epilepsy's forgotten symptom. Urban Health. 1982;11(1):30-32.

4. Betts TA. Epilepsy and the mental hospital. In: Reynolds E, Trimble M, editors. Epilepsy and Psychiatry. Vol. 3. Edinburgh: Churchill-Livingstone; 1982:60-82.

5. Biraben A, Taussig D, Thomas P, et al. Fear as the main feature of epileptic seizures. J Neurol Neurosurg Psychiatry. 2001;70(2):186. doi:10.1136/jnnp.70.2.186

6. Berg A, Berkovic S, Brodie M, et al. Revised terminology and concepts for organization of seizures and epilepsies: report of the ILAE commission on classification and terminology, 2005-2009. Epilepsia. 2010;51(4):676-685. doi:10.1111/j.1528-1167.2010.02 522.x

7. Hun C, Hok T, Bhalla D, Ros S, Chan S. Epilepsy: some controversies, some knowledge and some experience from Cambodia. Neurol India. 2014;62(6):606-609. doi:10.4103/0028-3886.149376

8. Bhalla D. Domestic Health Visiting: An Innovative Approach to Bridge Gaps in Epilepsy Care in Laos and Cambodia. Varetz, France; 2012.

9. Bhalla D. Epilepsy in Cambodia: Results and Perspectives. Ho Chi Minh, Vietnam; 2011.

10. Commission. Proposal for revised clinical and electroencephalographic classification of epileptic seizures. Epilepsia. 1981;22 (4):489-501. doi:10.1111/j.1528-1157.1981.tb06159.x

11. Lawshe CH. A quantitative approach to content validity. Pers Psychol. 1975;28(4):563-575. doi:10.1111/j.1744-6570.1975.tb013 93.x

12. French DP, Weinman J. Current issues and new directions in psychology and health-"assessing illness perceptions: beyond the IPQ". Psychol Health. 2008;23(1):5-9.

13. Brownlee S, Leventhal H, Leventhal EA. Regulation, self-regulation, and construction of the self in the maintenance of physical health. In: Boekarts M, Pintrich PR, Zeidner M, editors. Handbook of SelfRegulation. Vol. 12. San Diego, CA: Academic Press; 2000:369-416.
14. Hughes D, Bonnett L, Czanner G, Komárek A, Marson A, García-Fiñana M. Identification of patients who will not achieve seizure remission within 5 years on AEDs. Neurol. 2018;91(22): e2035-e44. doi:10.1212/WNL.0000000000006564

15. Ramaratnam S, Baker GA, Goldstein L. Psychological treatments for epilepsy. Cochrane Database Syst Rev. 2003;4:CD002029.

16. Archer R. Relationships between locus of control and anxiety. J Person Assess. 1980;43(6):617-626. doi:10.1207/s15327752jpa4306_10

17. Hulley SB, Cummings SR, Browner WS, Grady D, Newman TB. Designing Clinical Research: An Epidemiologic Approach. Philadelphia, USA: Lippincott Williams \& Wilkins; 2013:79-81.

18. McCall L, Clarke DM, Rowley G. Questionnaire to measure general practitioners' attitudes to their role in the management of patients with depression and anxiety. Aust Fam Physician. 2002;31:299-303.

19. Arif H, Buchsbaum R, Pierro J, et al. Comparative effectiveness of 10 antiepileptic drugs in adults with epilepsy. Arch Neurol. 2010;67 (4):408-415. doi:10.1001/archneurol.2010.49

20. Pal DK. Phenobarbital for childhood epilepsy: systematic review. Paediatr Perinat Drug Ther. 2006;7(1):31-42. doi:10.1185/ $146300905 \times 75361$

21. Bhalla D, Aziz H, Bergen D, et al. Undue regulatory control on phenobarbital-an important yet overlooked reason for the epilepsy treatment gap. Epilepsia. 2015;56(4):659-662. doi:10.1111/epi.12929

22. Uhlmann C, Fröscher W. Low risk of development of substance dependence for barbiturates and clobazam prescribed as antiepileptic drugs: results from a questionnaire study. CNS Neurosci Ther. 2009;15(1):24-31. doi:10.1111/j.1755-5949.2008.00073.x

23. Zhang LL, Zeng LN, Li YP. Side effects of phenobarbital in epilepsy: a systematic review. Epileptic Disord. 2011;13(4):349-365. doi:10.1684/epd.2011.0444

24. Perucca E. From clinical trials of antiepileptic drugs to treatment. Epilepsia Open. 2018;3:220-230. doi:10.1002/epi4.12239

25. Weisberg Y, DeYoung C, Hirsh J. Gender differences in personality across the ten aspects of the big five. Front Psychol. 2011;2:178-182. doi:10.3389/fpsyg. 2011.00178

26. Smoth W, Torstensson M. Gender differences in risk perception and neutralizing fear: towards resolving the paradoxes. $\mathrm{Br} \mathrm{J}$ Criminol. 1997;37(4):608-634. doi:10.1093/oxfordjournals.bjc.a014201

27. Roberts B, Luo J, Briley D, Chow P, Su R, Hill P. A systematic review of personality trait change through intervention. Psychol Bull. 2017;143(2):117-141. doi:10.1037/bul0000088

28. Holmes E, Hughes D, Morrison V. Predicting adherence to medications using health psychology theories: a systematic review of 20 years of empirical research. Value Health. 2014;17(8):863-876. doi:10.1016/j.jval.2014.08.2671

29. Smith TW, Williams PG. Personality and health: advantages and limitations of the five-factor model. J Pers. 1992;60(2):335-423. doi:10.1111/j.1467-6494.1992.tb00978.x

30. ASEM. Approaches to reducing stigma. In:Academies of Sciences E, and Medicine, editors. Ending Discrimination Against People with Mental and Substance Use Disorders: The Evidence for Stigma Change. Vol. 1. Washington, DC: National Academies Press (US); 2016:50-72

31. Jansen T, Rademakers J, Waverijn G, Verheij R, Osborne R, Heijmans $M$. The role of health literacy in explaining the association between educational attainment and the use of out-of-hours primary care services in chronically ill people: a survey study. BMC Health Serv Res. 2018;18(1):394-399. doi:10.1186/s12913-018-3197-4

32. Morton B, Richardson A, Duncan S. Sudden unexpected death in epilepsy (SUDEP): don't ask, don't tell? J Neurol Neurosurg Psychiatry. 2006;77(2):199-202. doi:10.1136/jnnp.2005.066852

33. Nouri S, Balish M. Sudden unexpected death in epilepsy. Medscape. 2015;8:e1187111.

34. Dumeier H, Neininger M, Bernhard M, et al. Providing teachers with education on epilepsy increased their willingness to handle acute seizures in children from one to 10 years of age. Acta Paediatr. 2017;106(11):1811-1816. doi:10.1111/apa.13938 
35. Nikbakht-Nasrabadi A, Sabzevari S, Negahban-Bonabi T. Iranian women's experiences of health information seeking barriers: a qualitative study in Kerman. Iran Red Crescent Med J. 2015;17 (2):251-256. doi:10.5812/ircmj.25156

36. Petrie K, Jago L, Devcich D. The role of illness perceptions in patients with medical conditions. Curr Opin Psychiatry. 2007;20:163-167. doi:10.1097/YCO.0b013e328014a871

37. Nikbakht-Nasrabadi A, Shabany-Hamedan M. Providing healthcare services at home-a necessity in Iran: a narrative review article. Iran J Pub Health. 2016;45(7):867-874.
38. Latiffah AL, Nor Afiah M, Shashikala S. Psychological well-being of the elderly people in Peninsular Malaysia. Int Med J. 2005;4:38-43.

39. Hesdorffer D,C, Tomson T, Benn E, Sander JW, Nilsson L, Langan Y. Do antiepileptic drugs or generalized tonic-clonic seizure frequency increase SUDEP risk? A combined analysis. Epilepsia. 2012;53 (2):249-252. doi:10.1111/j.1528-1167.2011.03354.x

\section{Publish your work in this journal}

Neuropsychiatric Disease and Treatment is an international, peerreviewed journal of clinical therapeutics and pharmacology focusing on concise rapid reporting of clinical or pre-clinical studies on a range of neuropsychiatric and neurological disorders. This journal is indexed on PubMed Central, the 'PsycINFO' database and CAS, and is the official journal of The International Neuropsychiatric Association (INA). The manuscript management system is completely online and includes a very quick and fair peer-review system, which is all easy to use. Visit http://www.dovepress.com/testimonials.php to read real quotes from published authors. 